\title{
Comparison of Microbial Communities Inside and Outside of a Denitrification Hotspot in Confined Groundwater
}

\author{
Xiangyong Zeng ${ }^{1 *}$, Takahiro Hosono ${ }^{2}$, Hiroto Ohta ${ }^{1}$, Takuro Niidome ${ }^{1}$, Jun Shimada ${ }^{1}$, \\ Shigeru Morimura ${ }^{1}$ \\ ${ }^{1}$ Graduate School of Science and Technology, and ${ }^{2}$ Priority Organization for Innovation and \\ Excellence, Kumamoto University, 2-39-1 Kurokami, Chuo-ku, Kumamoto City, Kumamoto \\ 860-0862, Japan \\ E-mail: \\ *Corresponding author: 15198294649@163.com \\ Takahiro Hosono: hosono@kumamoto-u.ac.jp \\ Hiroto Ohta: hiohta@gpo.kumamoto-u.ac.jp \\ Takuro Niidome: niidome@kumamoto-u.ac.jp \\ Jun Shimada: jshimada@sci.kumamoto-u.ac.jp \\ 17 Shigeru Morimura: morimura@gpo.kumamoto-u.ac.jp
}


Abstract A denitrification hotspot was detected in Kumamoto groundwater in a previous study, little information is concerned with the microbial community profile including denitrifier. Seven samples from inside and outside of the hotspot were collected to analyze the bacterial, archaeal, and denitrifier community using a cloning library approach. The results showed that the microbial diversity and distribution were distinct among the zones. Major operational taxonomic units closely related to Proteobacteria, Firmicutes, and Actinobacteria were found in the denitrification hotspot. Additionally, type I methylotrophic bacteria, such as Methylobacter and Methylomonas, only inhabited the hotspot zone. A positive association between methanogenic archaea and methylotrophic bacteria was observed. Interestingly, acidic ammonia-oxidizing archaea were detected in the neutral groundwater environment. In addition, gene-specific analysis targeting nirS indicated that the majority of denitrifiers belonged to the Proteobacteria including Sulfuritalea hydrogenivorans, Pseudomonas balearica and Sulfuricella denitrificans. Based on the comparative analysis of microbial communities and physiochemical parameters inside and outside of the denitrification hotspot, the anaerobic environment with organic compounds and nitrate could support the biotic reduction of nitrate in confined groundwater.

Keywords: Groundwater, 16S rDNA, nirS, Denitrification hotspot, Microbial community

\section{Introduction}

Nitrate $\left(\mathrm{NO}_{3}\right)$ pollution has become a significant issue in many countries owing to its adverse effects on human health and the environment, such as the eutrophication of surface water (Vitousek et al., 1997; Mason, 2002) and groundwater nitrate contamination (Beeson and Cook, 2004; Rao, 2006; Rivett et al., 2007). The microorganisms inhabiting either natural environments or artificial reactors have developed one or more mechanisms to reduce nitrate to maintain the $\mathrm{N}$-cycle balance. Anaerobic ammonia oxidation, dissimilatory nitrate reduction to ammonia, and denitrification process are ubiquitous in the natural environment and play critical roles in the attenuation of nitrate. Denitrification, the dissimilatory process of reduction of nitrate or nitrite to gaseous products $\left(\mathrm{N}_{2} \mathrm{O}\right.$ or $\left.\mathrm{N}_{2}\right)$ in the suboxic environment, is generally considered to be the major biological loss pathway for the conversion of fixed nitrogen from terrestrial aquatic ecosystems to the atmosphere (Devol, 2008). The functional genes $n i r S / K$, which encode a key enzyme for the reduction of nitrite to nitric oxide during the denitrification process, has been used extensively to analyze the denitrifier community in the environment.

Kumamoto City lies in the center of the Kyushu islands in southwest Japan, and is the largest groundwater utilization region in the country. About one million people in and around the city depend entirely on groundwater as the source of drinking water. Although Kumamoto City has had good performance with respect to groundwater protection in the past few decades, the concentration of $\mathrm{NO}_{3}$ in the groundwater has been increasing since the $1970 \mathrm{~s}$ as a result of the widespread application of chemical fertilizers and manure. Although the level of $\mathrm{NO}_{3}$ is still under the limit for healthy drinking water, the trend suggests a potential threat to the stability of the local environment and human health.

Given the importance of groundwater for local residents and the serious consequences of nitrate pollution, multiple studies performed in the Kumamoto groundwater studying area have examined groundwater, from various perspectives, such as geology (Miyoshi et al., 2009), hydrogeology (Taniguchi et al., 2003; Tanaka et al., 2010), and groundwater age and flow (Shimada, 2012). Those findings provided a basis for the analysis of microbiological 
communities and their mechanism of nitrate reduction. For example, Hosono et al. (2013) investigated the origin of nitrate and its attenuation mechanism using isotope labeling. Interestingly, the isotope data revealed a denitrification hotspot in the Kumamoto groundwater study area. Biogeochemical hotspots commonly occur at the boundaries or ecotones between two features in a landscape (McClain et al., 2003). Indeed, the denitrification hotspot characterized by Hosono et al. (2013) was located at a hill-plain border area. Furthermore, anaerobic autotrophic denitrifiers and methanogens were detected in the denitrification hotspot using $\delta^{13} \mathrm{C}, \delta^{15} \mathrm{~N}$ and $\delta^{34} \mathrm{~S}$ tracers (Hosono et al., 2014). Although many studies have analyzed denitrification hotspots and their microbial communities, to authors' knowledge, the profile of microbial community including denitrifiers in the Kumamoto groundwater area is still poorly understood. Basic knowledge regarding the microbial community and the taxa involved in the denitrification process is urgently needed.

Therefore, the objective of this study was to compare the microbial communities inside and outside of the denitrification hotspot using a cloning-library method and phylogenetic analysis to explain the occurrence of the denitrification hotspot. The results obtained in the present work provide additional information regarding the distribution of denitrifiers in regions of confined groundwater and further the mechanism of denitrification in the Kumamoto groundwater studying area.

\section{Materials and Method}

\subsection{Sampling sites}

The Kumamoto groundwater studying area, located at approximately $32.58 \mathrm{~N}$ to $32.92 \mathrm{~N}$ and $130.6 \mathrm{E}$ to $131.0 \mathrm{E}$, was defined as the area surrounded by the divide of Mount Aso (1592 m) to the east, the Midori River to the south, the Ariake Sea and Mount Kinpo to the west, and the Kikuchi River to the north (Hosono et al., 2013). This area includes two main groundwater flow lines: A-A' and B-B'. Two and five confined groundwater samples along the A-A' and B-B' lines, respectively, were collected from this area, as shown in Fig. 1, between August and November 2013. Samples B-I, B-T, and B-S were obtained from zone B2, where the denitrification hotspot was detected. Outside of the denitrification hotspot, samples B-Y and B-H were obtained in the recharge zone B1, and samples A-F and A-W were obtained from zone A2 along line A-A'; these specimens were used as control samples in the analysis.

\subsection{Measurement of hydrochemical parameters}

During sample collection, physicochemical parameters, such as depth, $\mathrm{pH}$, dissolved oxygen (DO), and oxidation-reduction potential (ORP), were directly measured in the field using handheld meters. In the lab, the concentration of dissolved organic carbon (DOC) was detected using TOC-VWS analyzer (Shimadzu, Japan) with the non-purgeable organic carbon method. Samples were acidified to below $\mathrm{pH} 3$, providing the removal of inorganic carbon (IC) as $\mathrm{CO}_{2}$. The DOC then was determined by subtracting the IC value from the Total Carbon (TC) measurement. Additionally, $\mathrm{NO}_{3}$ and $\mathrm{Cl}$ were measured by ion chromatography (Compact IC 761, Metrohm, Switzerland) using standard solutions; this technique had a detection limitation below $0.05 \mathrm{mg} \mathrm{l}^{-1}$. Approximately 101 of each water sample were filtered through the 0.22- $\mu \mathrm{m}$ Sterivex sterile filter unit (Millipore, Billerica, MA, USA) to obtain microorganisms for DNA extraction.

\subsection{DNA extraction and cloning-library analysis}

The total DNA from seven filtered samples was extracted using the PowerWater Sterivex $^{\text {TM }}$ DNA Isolation Kit (MO BIO, Carlsbad, CA, USA) according to the manufacturer's instructions. Subsequently, PCR amplification was performed. The primer sets for PCR and corresponding mixture and conditions during amplification were shown in 
the supplementary Table S1. The purified PCR products were inserted into the pT7 Blue Vector (Novagen, Cambridge, MA, USA) and transferred into competent cell Escherichia coli DH5 $\alpha$ according to the manufacturer's protocols. After transformation, plasmid extraction was subsequently performed using the Wizard SV Minipreps DNA Purification System (Promega, Madison, WI, USA). Both EcoRI and PstI restriction enzymes were used to identify the positive clones as specified by the manufacturer. Following sequencing and chimera-checking (Edgar et al., 2011), operational taxonomic unit (OTU) classification was performed with Mothur (Schloss et al., 2009) and the nearest strains of the representative OTU clones were searched in NCBI database. Finally, the phylogenetic tree was built using MEGA 5.0 with the neighbor-joining method (Tamura et al., 2011).

\subsection{Accession numbers}

The bacterial, archaeal and nirS sequences used to detect the OTUs in this work were submitted to the DNA Data Bank of Japan (DDBJ) as accession numbers LC082102LC082131.

\section{Results and Discussion}

\subsection{Characteristics of groundwater samples}

The hydrochemical parameters of the seven samples are summarized in Table 1. Along A-A', the concentration of $\mathrm{O}_{2}$ and ORP decreased from more than $2.0 \mathrm{mg} \mathrm{l}^{-1}$ and $200 \mathrm{mV}$ in samples $(\mathrm{n}=2)$ upstream of the hotspot to less than $1 \mathrm{mg} \mathrm{l}^{-1}$ and negative in samples $(\mathrm{n}=3)$ inside of the hotspot respectively. The changing tendency was consistent with a previous study (Li et al., 2011). Additionally, the DOC concentration increased abruptly from 0.4 to $2.07 \mathrm{mg} \mathrm{l}^{-1}$ while the $\mathrm{Cl}$ concentration decrease from 64.4 to $4.4 \mathrm{mg} \mathrm{l}^{-1}$ between the $\mathrm{B} 1$ and $\mathrm{B} 2$ zones, possibly due to the infiltration of freshwater with DOC from the surface water. The subsequent decrease of DOC, often used as a carbon source and electron donor, from upstream to downstream indicated stimulation of heterotrophic bacteria including denitrifiers and competition between those organisms in the hotspot (Zhang et al., 2016). The concentration of $\mathrm{NO}_{3}$ fell below detectable limits in the $\mathrm{B} 2$ zone; depletion of nitrate confirmed the existence of the denitrification hotpsot. Conversely, the $\mathrm{NO}_{3}$ concentrations in the A2 zone increased when compared samples A-F and A-W (10.3 $\mathrm{mg} \mathrm{l}^{-1}$ and $19.9 \mathrm{mg} \mathrm{l}^{-1}$, respectively). The high ORP and DO concentration detected in A-W indicated that processes at this site were strictly aerobic.

\subsection{Phylogenetic analysis of bacterial 16S rDNA}

A total of 199 clones, including 20, 18, 30, 32, 31, 33, and 35 clones obtained from samples A-F, A-W, B-Y, B-H, B-I, B-T, and B-S, respectively, were subjected to cloning analysis after chimera checking and classified into 59 OTUs (similarity $>97 \%$ ). The main OTUs defined as those represented by more than three clones corresponded to 138 clones in total; these OTUs were used to build a phylogenetic tree (Fig. 2). These clones clustered into five groups: $\alpha$-Proteobacteria, $\beta$-Proteobacteria, $\gamma$-Proteobacteria, Firmicutes and Actinobacteria. The most numerous bacteria in the present study were Proteobacteria, which was consistent with previous studies characterizing microbial communities in deep bedrock (Larentis et al., 2015), and in both confined and unconfined aquifer ecosystems located under a dairy farming region (Smith et al., 2012).

In the class $\alpha$-Proteobacteria, LC082107 was the largest group consisting of 31 and 23 clones from the B1 and B2 zones, respectively, and showed $99 \%$ similarity to Methylobacterium mesophilicum. This organism, originally isolated from the pink film in a bathroom, is a gram-negative, strictly aerobic, pink-pigmented, facultative methylotrophic bacterium (Yano et al., 2013). This type II methylotrophic bacterium can utilize methanol, 
formate, and other $\mathrm{C} 1$ sources via the serine pathway. In the $\gamma$-Proteobacteria cluster, LC082102 and LC082104 consisting of 4 and 11 clones both from the B2 zone displayed 98\% and 91\% identity to Methylomonas rubra and M. paludis, respectively. M. paludis is an aerobic methylotrophic bacterium, originally isolated from an acidic (pH 3.9) Sphagnum peat bog in northeastern Russia, possesses a particular methane monooxygenase enzyme and utilizes only methane and methanol (Danilova et al., 2013). The nearest strain of LC082103 owing five clones from the B2 zone was Methylobacter psychrophilus. Both Methylomonas and Methylobacter are type I methylotrophic bacteria that can utilize $\mathrm{C} 1$ compounds via the ribulose monophosphate pathway. Although the B1 and B2 zones are both suboxic environments, no clones corresponding to anaerobic methanotrophic archaea were found in the present study, and the diversity of methanogens was lower than that observed in a previous study (Zhou et al., 2015). The growth of type II methylotrophs is favored under low-oxygen, high-methane conditions, and type I methylotrophs outcompete type II methylotrophs at low-methane concentrations (Graham et al., 1993). However, the wide distribution of the Methylobacterium spp. in the B1 and B2 zones where have wide ranges of DO and DOC suggested that these type II methylotrophs easily adapt to changing environments, a hypothesis that is not consistent with previous findings.

Among the class $\beta$-Proteobacteria, LC082106 owing five clones was associated with Sulfuritalea hydrogenivorans sk $43 \mathrm{H}$ with $99 \%$ identity. This strain was isolated from freshwater lake sediments in Japan; although this organism originally was characterized as a facultative anaerobe, it was still found in sample A-W with DO concentration of $8.08 \mathrm{mg} \mathrm{l}^{-1}$ (Table 1). S. hydrogenivorans sk43H can oxidize thiosulfate, elemental sulfur, or hydrogen as a sole energy sources for autotrophic growth, alternatively, this bacterium can oxidize acetate, benzoate, pyruvate, and succinate for heterotrophic growth, utilizing nitrate as an electron acceptor (Kojima and Fukui, 2010). The closest strain to representative LC082111 was Bacillus subtilus in the phylum Firmicutes, with $100 \%$ identity. Some B. subtilus strains have been isolated from ammonia-rich wastewater and are able to directly covert ammonia to gaseous nitrogen under aerobic conditions (Kim et al., 2005; Yang et al., 2011). Gram-positive bacteria, including Bacillus, have been shown to be involved in the denitrifying process in wastewater treatment systems and paddy soil (Verbaendert et al., 2011).

\subsection{Distribution of bacterial 16S rDNA}

The distribution of the main genus and family in each zone is shown in Fig. 3. Methylotrophs, Firmicutes, and Corynebacterium were distributed in both B1 and B2, along the B-B' line. However, members of the genera Curvibacter and Sulfuritalea which belong to the class $\beta$-Proteobacteria, were found primarily in the A2 zone. Interestingly, type I methylotrophic bacteria, such as Methylobacter spp. and Methylomonas spp., the family Methylococcaceae only inhabited the B2 zone. Conversely, another type II methylotroph, genus methylocystis was found in the A2 zone, though this organism was apparently less abundant (i.e., represented by fewer clones). In addition, it was clear that the bacterial diversity of the B2 zone was much higher than that of the other two zones. Notably, among the other genera, despite low clone numbers, the sequences closely related to denitrifiers such as Pseudomonas stutzeri in sample B-Y and Sideroxydans lithotrophicus in sample B-I were found in the present study.

3.4 Phylogenetic tree of archaeal 16S rDNA

After chimera checking, 144 non-chimeric archaeal sequences was isolated, including $22,16,21,15,22,25$, and 23 clones from samples A-F, A-W, B-Y, B-H, B-I, B-T, and B-S, respectively. These sequences were classified into 50 OTUs with the cutoff of 0.03 . Thirteen major OTUs with more than two clones were selected to build the phylogenetic tree after 
identifed the closest known strains in BLAST. As shown in the supplementary Fig. S1, these sequences grouped into two clusters (phyla): Euryarchaeota and Thaumarchaeota.

Representative LC082112 with two and five clones found in the B1 and B2 zones, respectively, were associated with Methanobacterium sp. SA-12 with 99\% identity. Likewise, LC082113 and LC082114 showed 98\% and 99\% identity to known archaea M. aarhusense strain H2-LR and M. flexile strain GH, respectively. Methane-producing archaea utilize $\mathrm{H}_{2} / \mathrm{CO}_{2}$ or acetate to produce methane in the strictly anaerobic environments (Thauer, 1998), where the methane then is oxidized by methylotrophic bacteria. The cloning-library analysis suggested that the ratios of methane-producing archaeal clones to total archaeal clones were $12 \%, 63 \%$, and $0 \%$ in zones $\mathrm{B} 1, \mathrm{~B} 2$, and $\mathrm{A} 2$, respectively, which appeared to correlate with the distribution of methane-assimilating bacteria such as Methylobacter and Methylomonas. Previous isotopic analysis provided evidence for the occurrence of the methane-producing reaction in the B2 zone (Hosono et al., 2014), and this interpretation is supported by the distribution of Methanobacterium in the B2 zone in the present study.

Members of Thaumarchaeota, another archaeal phylum, also were obtained during analysis of archaeal 16S rDNA. A total of 32 clones belonging to Thaumarchaeota were primarily found the B1 and A2 zones, where the DO concentration was relatively high. LC082120 and LC082121 displayed 96\% and 90\% identity to Candidatus Nitrososphaera sp. EN76, respectively. This ammonia-oxidizing archaeon (AOA) originally was isolated from soil and can utilize ammonia or urea as an energy source; the organism is capable of growth at high ammonia concentrations (Tourna et al., 2011). LC082123 and LC082124 enhancing 3 and 16 clones showed $93 \%$ and $100 \%$ identity to Candidatus Nitrosotalea devanaterra isolate $\mathrm{Nd} 1$, respectively. Isolated and cultivated from acidic agricultural soil, this archaeon was involved in the ammonia oxidization process (Lehtovirta-Morley et al., 2011; 2014). Intriguingly, though originally identified as an acidophilic archaeon, Candidatus $N$. devanaterra was detected in the present study in confined groundwater where is neutral environment. Previous studies have demonstrated that AOA inhabit not only soil (Prosser and Nicol, 2012), but also groundwater systems (Rogers and Casciotti, 2010), and that AOA play more important roles in the nitrification process than ammonia-oxidizing bacteria (Prosser and Nicol, 2008; Rogers and Casciotti, 2010). However, few studies have reported the detection of acidophilic archaea Candidatus $N$. devanaterra in the neutral groundwater environments. The occurrence of this organism in confined groundwater remains to be further characterized in future studies.

\subsection{Phylogenetic analysis of nirS}

A total of 59 nirS-positive clones were obtained, including 3, 3, 19, 20, and 14 clones from sample B-Y, B-I, B-T, B-S and A-F, respectively. The major OTUs as well as their closest strains are summarized in the supplementary Table S2. These nirS-related sequences showed $77-99 \%$ identity to the reference strains. Consistent with previous studies (Iribar et al., 2008; Katsuyama et al., 2013), all nirS-related sequences were derived from known denitrifying Proteobacteria except for the uncultured and poorly characterized bacterial strain designated "Clone J16".

LC082127 was associated with Sulfuricella denitrificans skB26 with $82 \%$ identity. $S$. denitrificans skB26, isolated from anoxic freshwater lake sediment in Japan, is a novel facultative anaerobic sulfur-oxidizing bacterium. This organism can oxidize elemental sulfur or thiosulfate to sulfate under micro-aerobic conditions utilizing nitrate as an electron acceptor during reduction of nitrate to nitrogen (Kojima and Fukui, 2010). Similarly, LC082129 showed 94\% identity to Sulfuritalea hydrogenivorans sk43H. This strain was also isolated from freshwater lake sediment in Japan, and is a facultative anaerobic bacterium that exhibits autotrophic growth only under anaerobic conditions. The isolate can use thiosulfate, elemental sulfur or hydrogen as a sole energy sources for autotrophic growth with nitrate as 
an electron acceptor (Kojima and Fukui, 2011). The nearest strain of LC082130 was

263 Pseudomonas balearica DSM 6083 originally isolated from sewage water with 99\% identity.

264 This organism can oxidize inorganic sulfur or thiosulfate compounds to tetrathionate under denitrifying conditions using $\mathrm{NO}_{3}, \mathrm{NO}_{2}$, or $\mathrm{N}_{2} \mathrm{O}$ as an electron acceptor (Sorokin et al., 1999). LC082131 including 28 clones accounted for about half of all nirS-related sequences obtained in the present study. The closest strain of LC082131 was the uncultured bacterium clone J16 (JF966879.1) with 99\% identity. Though little is known about this denitrifying bacterium, this sequence was detected in both the B1 and B2 zones in the present study. Therefore, It was speculated that this type of denitrifier plays an important role in the depletion of nitrate within the denitrification hotspot. However, the $16 \mathrm{~S}$ rDNA and nirS analysis suggested the presence of large numbers of denitrifiers in sample A-F with relatively low level of DO and ORP and elevated level of $\mathrm{NO}_{3}$. Comparison of the denitrifier species and bacterial community structure between samples A-F and B-S is expected to clarify the occurrence and activity of the denitrification process at this study's hotspot.

\section{Conclusions}

The main purpose of this study was to characterize, using hydrochemical data and microbial diversity and taxon distributions, the microbial community associated with biotic denitrification process in confined groundwater. Although relatively few clones were obtained in this study despite repeated attempts and lack of quantitative data, the obtained cloning data provide an approximation of the microbial community profile inside and outside of the denitrification hotspot. Notably, kinds of denitrifiers were detected including autotrophic and heterotrophic denitrifier. Additionally, methane cycle-associated methylotrophs and methanogens were detected in the denitrification hotspot along with these denitrifiers. Therefore, it was speculated that active denitrification with the methane cycling occurs under anaerobic conditions, and that this biotic process is maintained by continuous DOC contamination in the B2 zone. Interestingly, AOA were found in the neutral confined aquifer environment. The comparative analysis of the microbial distribution and corresponding environment variables in each zone provided useful knowledge about microorganisms, including denitrifiers, involved in nitrate reduction in Kumamoto groundwater. Investigation of denitrifier activity between these denitrifiers and isolation and enrichment of AOA will be performed in the near future.

\section{Acknowledgements}

This research was supported by the CREST Project (JST: Japan Science and Technology Agency) and the China Scholar Council. We are grateful to the Kumamoto City government for providing groundwater samples and to Dr. Kotaro Nakata for the DOC analysis.

\section{References}

Beeson, S., Cook, M.C., 2004. Nitrate in groundwater: a water company perspective. Quarterly Journal of Engineering Geology and Hydrogeology 37, 261-270.

Braker, G., Fesefeldt, A., Witzel, K.P., 1998. Development of PCR primer systems for amplification of nitrite reductase genes (nirK and nirS) to detect denitrifying bacteria in environmental samples. Applied and Environmental Microbiology 64, 3769-3775.

Danilova, O.V., Kulichevskaya, I.S., Rozova, O.N., Detkova, E.N., Bodelier, P.L.E., Trotsenko, Y.A., Dedysh, S.N., 2013. Methylomonas paludis sp nov., the first acid-tolerant member of the genus Methylomonas, from an acidic wetland. International Journal of Systematic and Evolutionary Microbiology 63, 2282-2289. 
Devol, A.H., 2008. Chapter 6 - Denitrification Including Anammox, In: Capone, D.G., Bronk,

D.A., Mulholland, M.R., Carpenter, E.J. (Eds.), Nitrogen in the Marine Environment (2nd Edition). Academic Press, San Diego, pp. 263-301.

Edgar, R.C., Haas, B.J., Clemente, J.C., Quince, C., Knight, R., 2011. UCHIME improves sensitivity and speed of chimera detection. Bioinformatics 27, 2194-2200.

Graham, D.W., Chaudhary, J.A., Hanson, R.S., Arnold, R.G., 1993. Factors Affecting Competition between Type- and Type- Methanotrophs in 2-Organism, Continuous-Flow Reactors. Microbial Ecology. 25, 1-17.

Hosono, T., Tokunaga, T., Kagabu, M., Nakata, H., Orishikida, T., Lin, I.T., Shimada, J., 2013. The use of $\delta^{15} \mathrm{~N}$ and $\delta^{18} \mathrm{O}$ tracers with an understanding of groundwater flow dynamics for evaluating the origins and attenuation mechanisms of nitrate pollution. Water Research 47, 2661-2675.

Hosono, T., Tokunaga, T., Tsushima, A., Shimada, J., 2014. Combined use of $\delta^{13} \mathrm{C}, \delta^{15} \mathrm{~N}$, and $\delta^{34} \mathrm{~S}$ tracers to study anaerobic bacterial processes in groundwater flow systems. Water Research 54, 284-296.

Iribar, A., Sanchez-Perez, J.M., Lyautey, E., Garabetian, F., 2008. Differentiated free-living and sediment-attached bacterial community structure inside and outside denitrification hotspots in the river-groundwater interface. Hydrobiologia 598, 109-121.

Jurgens, G., Lindstrom, K., Saano, A., 1997. Novel group within the kingdom Crenarchaeota from boreal forest soil. Applied and Environmental Microbiology 63, 803-805.

Katsuyama, C., Nashimoto, H., Nagaosa, K., Ishibashi, T., Furuta, K., Kinoshita, T., Yoshikawa, H., Aoki, K., Asano, T., Sasaki, Y., Sohrin, R., Komatsu, D.D., Tsunogai, U., Kimura, H., Suwa, Y., Kato, K., 2013. Occurrence and potential activity of denitrifiers and methanogens in groundwater at $140 \mathrm{~m}$ depth in Pliocene diatomaceous mudstone of northern Japan. FEMS Microbiology Ecology. 86, 532-543.

Kim, J.K., Park, K.J., Cho, K.S., Nam, S.W., Park, T.J., Bajpai, R., 2005. Aerobic nitrification-denitrification by heterotrophic Bacillus strains. Bioresource Technology 96, 1897-1906.

Kojima, H., Fukui, M., 2010. Sulfuricella denitrificans gen. nov., sp nov., a sulfur-oxidizing autotroph isolated from a freshwater lake. International Journal of Systematic and Evolutionary Microbiology 60, 2862-2866.

Kojima, H., Fukui, M., 2011. Sulfuritalea hydrogenivorans gen. nov., sp nov., a facultative autotroph isolated from a freshwater lake. International Journal of Systematic and Evolutionary Microbiology 61, 1651-1655.

Larentis, M., Psenner, R., Alfreider, A., 2015. Prokaryotic community structure in deep bedrock aquifers of the Austrian Central Alps. Antonie Van Leeuwenhoek 107, 687-701.

Lehtovirta-Morley, L.E., Ge, C., Ross, J., Yao, H., Nicol, G.W., Prosser, J.I., 2014. Characterisation of terrestrial acidophilic archaeal ammonia oxidisers and their inhibition and stimulation by organic compounds. FEMS Microbiology Ecology 89, 542-552.

Lehtovirta-Morley, L.E., Stoecker, K., Vilcinskas, A., Prosser, J.I., Nicol, G.W., 2011. Cultivation of an obligate acidophilic ammonia oxidizer from a nitrifying acid soil. Proceedings of the National Academy of Sciences of United States of America 108, 15892-15897.

Li, F., Zhang, Q., Tang, C., Fukumoto, K., Ota, H., 2011. Denitrifying bacteria and hydrogeochemistry in a natural wetland adjacent to farmlands in Chiba, Japan. Hydrological Processes 25, 2237-2245.

Mason, C., 2002. Biology of Freshwater pollution (4th ed.), Benjamin Cummings, San Francisco.

McClain, M.E., Boyer, E.W., Dent, C.L., Gergel, S.E., Grimm, N.B., Groffman, P.M., Hart, S.C., Harvey, J.W., Johnston, C.A., Mayorga, E., McDowell, W.H., Pinay, G., 2003. 
Biogeochemical Hot Spots and Hot Moments at the Interface of Terrestrial and Aquatic Ecosystems. Ecosystems 6, 301-312.

Miyoshi, M., Furukawa, K., Shinmura, T., Shimono, M., Hasenaka, T., 2009. Petrography and whole-rock geochemistry of pre-Aso lavas from the caldera wall of Aso volcano, central Kyushu. Journal of the Geological Society of Japan 115, 672-687.

Prosser, J.I., Nicol, G.W., 2008. Relative contributions of archaea and bacteria to aerobic ammonia oxidation in the environment. Environmental Microbiology 10, 2931-2941.

Prosser, J.I., Nicol, G.W., 2012. Archaeal and bacterial ammonia-oxidisers in soil: the quest for niche specialisation and differentiation. Trends in Microbiology 20, 523-531.

Rao, N.S., 2006. Nitrate pollution and its distribution in the groundwater of Srikakulam district, Andhra Pradesh, India. Environmental Geology 51, 631-645.

Rivett, M.O., Smith, J.W.N., Buss, S.R., Morgan, P., 2007. Nitrate occurrence and attenuation in the major aquifers of England and Wales. Quarterly Journal of Engineering Geology and Hydrogeology 40, 335-352.

Rogers, D.R., Casciotti, K.L., 2010. Abundance and Diversity of Archaeal Ammonia Oxidizers in a Coastal Groundwater System. Applied and Environmental Microbiology 76, 7938-7948.

Schloss, P.D., Westcott, S.L., Ryabin, T., Hall, J.R., Hartmann, M., Hollister, E.B., Lesniewski, R.A., Oakley, B.B., Parks, D.H., Robinson, C.J., Sahl, J.W., Stres, B., Thallinger, G.G., Van Horn, D.J., Weber, C.F., 2009. Introducing mothur: Open-Source, Platform-Independent, Community-Supported Software for Describing and Comparing Microbial Communities. Applied and Environmental Microbiology 75, 7537-7541.

Shimada, J., 2012. Sustainable management of groundwater resources for 700,000-plus residents: a practical example of the transboundary management of groundwater resources in the Kumamoto area, Japan, In: Taniguchi, M., Shiraiwa, T. (Eds.), The Dilemma of Boundaries: Toward a New Concept of Catchment. Springer, Japan, pp. 235-246.

Smith, R.J., Jeffries, T.C., Roudnew, B., Fitch, A.J., Seymour, J.R., Delpin, M.W., Newton, K., Brown, M.H., Mitchell, J.G., 2012. Metagenomic comparison of microbial communities inhabiting confined and unconfined aquifer ecosystems. Environmental Microbiology 14, 240-253.

Sorokin, D.Y., Teske, A., Robertson, L.A., Kuenen, J.G., 1999. Anaerobic oxidation of thiosulfate to tetrathionate by obligately heterotrophic bacteria, belonging to the Pseudomonas stutzeri group. FEMS Microbiology Ecology 30, 113-123.

Tamura, K., Peterson, D., Peterson, N., Stecher, G., Nei, M., Kumar, S., 2011. MEGA5: Molecular Evolutionary Genetics Analysis Using Maximum Likelihood, Evolutionary Distance, and Maximum Parsimony Methods. Molecular Biology and Evolution 28, 2731-2739.

Tanaka, K., Funakoshi, Y., Hokamura, T., Yamada, F., 2010. The role of paddy rice in recharging urban groundwater in the Shira River Basin. Paddy and Water Environment 8, 217-226.

Taniguchi, M., Shimada, J., Uemura, T., 2003. Transient effects of surface temperature and groundwater flow on subsurface temperature in Kumamoto Plain, Japan. Phycis and Chemistry of the Earth 28, 477-486.

Thauer, R.K., 1998. Biochemistry of methanogenesis: a tribute to Marjory Stephenson. Microbiol-Uk 144, 2377-2406.

Tourna, M., Stieglmeier, M., Spang, A., Konneke, M., Schintlmeister, A., Urich, T., Engel, M., Schloter, M., Wagner, M., Richter, A., Schleper, C., 2011. Nitrososphaera viennensis, an ammonia oxidizing archaeon from soil. Proceedings of the National Academy of Sciences of the United states of America 108, 8420-8425. 
409 Verbaendert, I., De Vos, P., Boon, N., Heylen, K., 2011. Denitrification in Gram-positive 410 bacteria: an underexplored trait. Biochemical Society Transactions 39, 254-258.

411 Vitousek, P.M., Aber, J.D., Howarth, R.W., Likens, G.E., Matson, P.A., Schindler, D.W., 412 Schlesinger, W.H., Tilman, D., 1997. Human alteration of the global nitrogen cycle: Sources 413 and consequences. Ecological Applications 7, 737-750.

414 Weisburg, W.G., Barns, S.M., Pelletier, D.A., Lane, D.J., 1991. 16s Ribosomal DNA 415 Amplification for Phylogenetic Study. Journal of Bacteriology 173, 697-703.

416 Yang, X.P., Wang, S.M., Zhang, D.W., Zhou, L.X., 2011. Isolation and nitrogen removal 417 characteristics of an aerobic heterotrophic nitrifying-denitrifying bacterium, Bacillus subtilis 418 A1. Bioresource Technology 102, 854-862.

419 Yano, T., Kubota, H., Hanai, J., Hitomi, J., Tokuda, H., 2013. Stress Tolerance of 420 Methylobacterium Biofilms in Bathrooms. Microbes and Environment 28, 87-95.

421 Zhang, D., Vahala, R., Wang, Y., Smets, B.F., 2016. Microbes in biological processes for 422 municipal landfill leachate treatment: Community, function and interaction. International 423 Biodeterioration and Biodegradation, 1-9 (in press).

424 Zhou, Z.C., Chen, J., Cao, H.L., Han, P., Gu, J.D., 2015. Analysis of methane-producing and 425 metabolizing archaeal and bacterial communities in sediments of the northern South China 426 Sea and coastal Mai Po Nature Reserve revealed by PCR amplification of mcrA and pmoA 427 genes. Frontiers in microbiology 5, 1-15. 
Table 1 Hydrochemical parameters for seven deep groundwater samples obtained from Kumamoto groundwater studying area

\begin{tabular}{|c|c|c|c|c|c|c|c|c|c|c|}
\hline Zone & Sample name & Longitude (E) & Latitude (N) & Well depth (m) & $\mathrm{pH}$ & $\mathrm{DO}\left(\mathrm{mg} \mathrm{l}^{-1}\right)$ & $\mathrm{DOC}\left(\mathrm{mg} \mathrm{l}^{-1}\right)$ & ORP $(\mathrm{mV})$ & $\mathrm{NO}_{3}\left(\mathrm{mg} \mathrm{l}^{-1}\right)$ & $\mathrm{Cl}\left(\mathrm{mg} \mathrm{l}^{-1}\right)$ \\
\hline \multirow[t]{2}{*}{$\mathrm{A} 2$} & A-F & 130.82166 & 32.82062 & 90 & 7.43 & 2.37 & 1.29 & 65 & 10.3 & 9.8 \\
\hline & A-W & 130.81228 & 32.81715 & 70 & 7.24 & 8.08 & 5.36 & 342 & 19.9 & 9.2 \\
\hline \multirow[t]{2}{*}{ B1 } & B-Y & 130.71992 & 32.84569 & 124 & 6.45 & 3.17 & 0.75 & 221 & 0.8 & 34.9 \\
\hline & B-H & 130.72133 & 32.84175 & 131 & 6.87 & 2.31 & 0.4 & 266 & 2.4 & 64.4 \\
\hline \multirow[t]{3}{*}{ B2 } & $\mathrm{B}-\mathrm{T}$ & 130.71411 & 32.81795 & 50 & 7.22 & 0.83 & 2.07 & -70 & 0 & 4.4 \\
\hline & B-1 & 130.69850 & 32.82118 & 91 & 7.94 & 0.1 & 0.3 & -261 & 0 & 3.8 \\
\hline & B-S & 130.71570 & 32.80015 & 65 & 7.67 & 0.6 & 0.59 & -199 & 0 & 15.2 \\
\hline
\end{tabular}




\section{List of figure captions}

Fig. 1 Sampling sites in the Kumamoto groundwater study area.

Fig. 2 Phylogenetic analysis of the main operational taxonomic units (OTUs), defined as those represented by more than three bacterial $16 \mathrm{~S}$ rDNA clones.

The strains most closely related to each clone were identified by BLAST searches; uncultured/environmental sample were excluded. Both the retrieved clones and their closely related isolates in the BLAST search were used to build a phylogenetic tree with the neighbor-joining method. The zone name and number in parentheses next to the accession number indicate the number of clones obtained in each zone. The numbers at the nodes show the confidence levels of the clustering based on 1000 bootstrap replicates

Fig. 3 Distribution of the main bacterial genera and family to which the clones affiliated in each zone.

Supplementary Fig. S1 Phylogenetic analysis of the main OTUs, defined as those represented by more than two archaeal 16S rDNA clones.

The strains most closely related to each of the obtained clones were identified by BLAST searches; uncultured/environmental sample were excluded. Both the retrieved clones and their closest clones in the BLAST analysis were used to build a phylogenetic tree with the neighbor-joining method. The zone name and number in parentheses near the accession number indicate the number of clones obtained from each zone. Numbers at the nodes show the confidence levels of the clustering based on 1000 bootstrap replicates. 


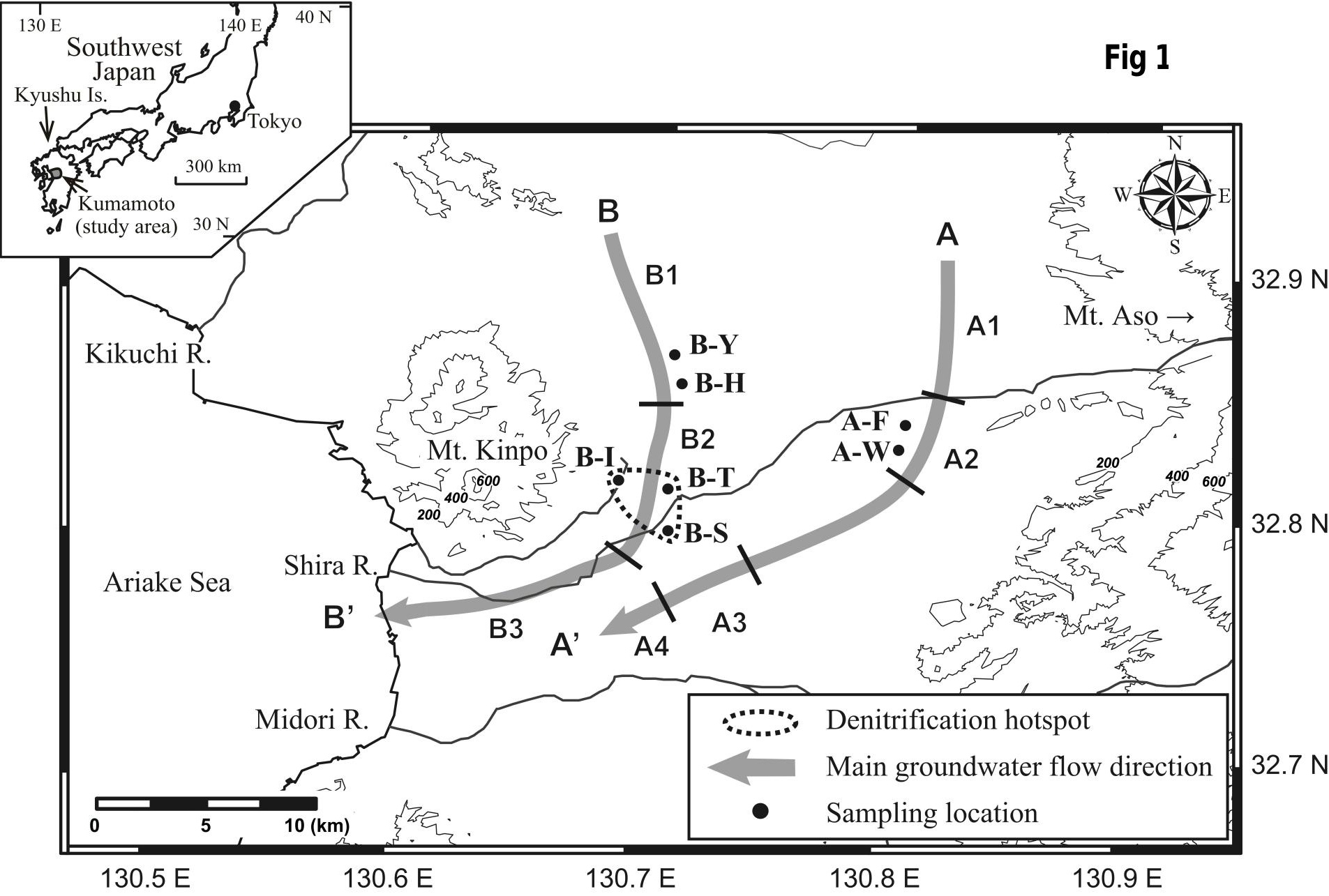




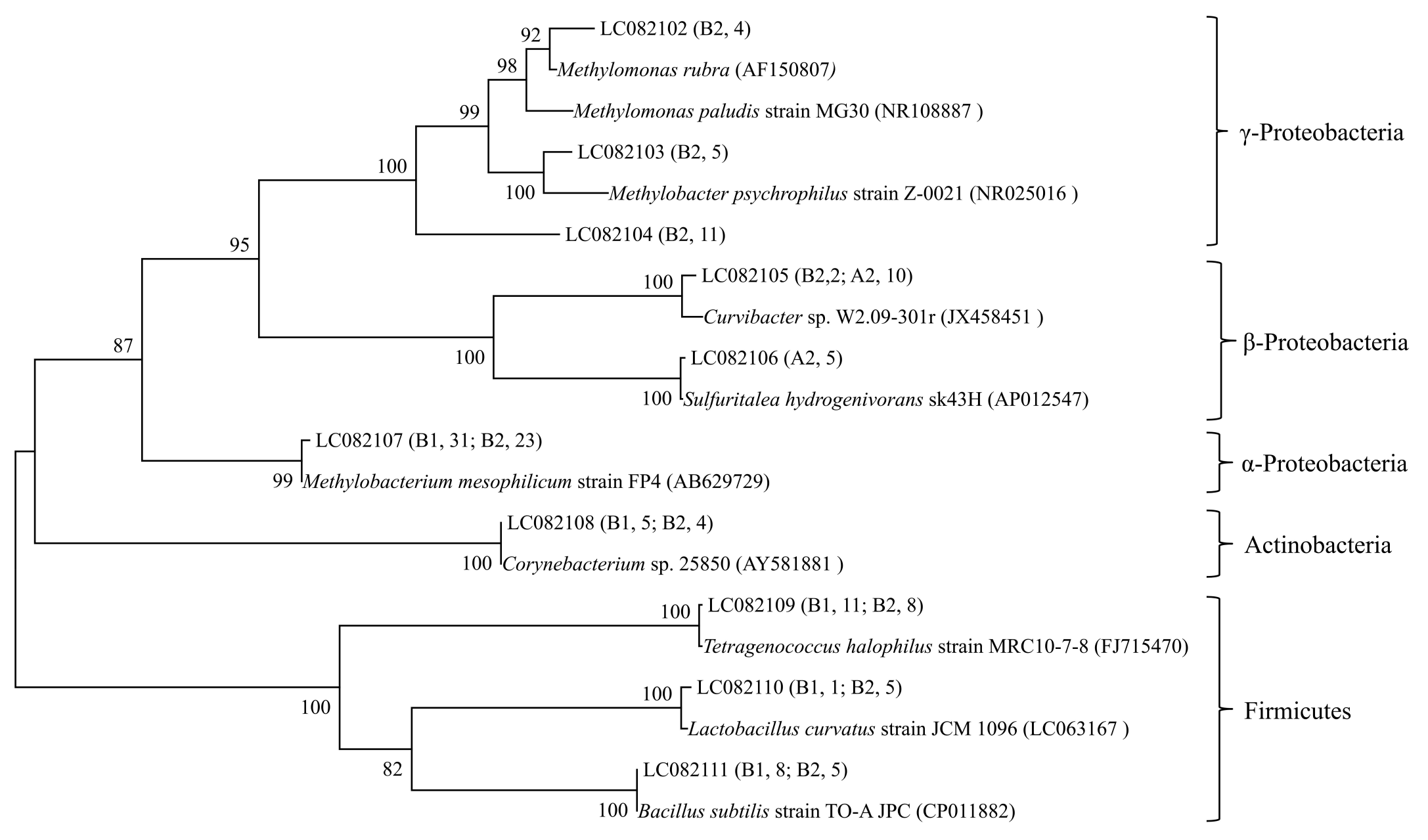




\section{Graphical abstract}

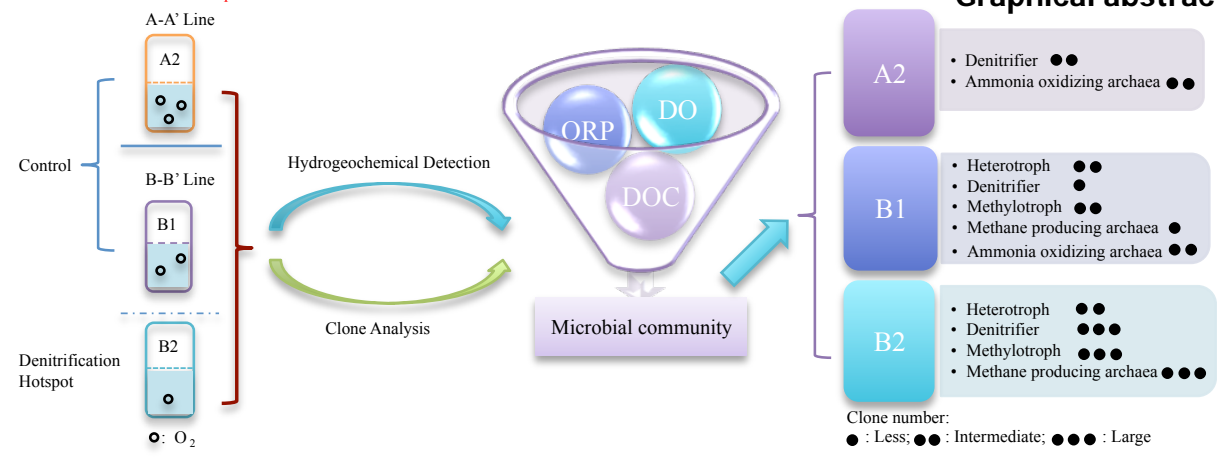

